\title{
Sorption and Desorption of Atrazine on Natural Bentonite and Organically Modified Bentonite
}

\author{
Mohamed A Osman ${ }^{1}$, Fawzy M. Kishk ${ }^{2}$, Abdalla A. Moussa ${ }^{1}$, and Hesham M. Gaber ${ }^{2}$
}

\begin{abstract}
In order to increase the effectiveness of bentonite clay in the retention of atrazine, natural bentonite clay was modified using humic acid and hexadecyltrimethylammonium bromide (HDTMA) as the intercalation agent and a cationic surfactant at $100 \%$ of the cation exchange capacity. Such organic modification changes the nature of clay from hydrophilic to hydrophobic, which insures surfactant loading. The performance of the natural and modified bentonite was evaluated in terms of elemental analysis, BET surface area, X-ray diffraction (XRD), FTIR spectroscopy, and thermogravimetric analysis (TGA). The batch equilibrium technique was applied to conduct atrazine adsorption/desorption isotherms with the natural and the modified bentonite. The data fitted well to the simple linear and Freundlich adsorption isotherms while desorption data agreed with Freundlich adsorption only. Desorption kinetic was successfully fitted with the first order reaction model. Natural bentonite was a poor adsorbent of atrazine with distribution coefficient of $K_{d}=3.07 \pm 0.04 \mathrm{~L} \mathrm{~kg}^{-1}$. The complexion with humic acid did not improve atrazine adsorption on bentonite, $K_{d}=2.15 \pm 0.14 \mathrm{~L} \mathrm{~kg}^{-1}$, whereas, the HDTMA-bentonite exhibited high affinity to sorb atrazine with $K_{d}$ value of $197.97 \pm 0.77 \mathrm{~L} \mathrm{~kg}^{-1}$. Natural bentonite and humic-bentonite clearly exhibited nonsingularity of sorption/desorption isotherms. The desorption curve of HDTMA-bentonite revealed that the sorption of atrazine is reversible with no hysteresis. These results indicate the potentiality of HDTMA-bentonite for environmental applications.
\end{abstract}

Keywords: Bentonite, Organoclays, HDTMA-Br, Humic acid, Atrazine, Adsorption, Desorption, Freundlich Isotherm.

\section{INTRODUCTION}

Pesticides discharged from agricultural soils are a significant class of environmental pollutants because of their toxicity even at trace levels. The removal of these pesticides from drainage water is required for sustaining environmental natural resources (Cara and Jităreanu 2015). Numerous techniques such as adsorption, degradation, photocatalytic, electrochemical degradation, oxidation, membrane filtration, nanofiltration are applied to decrease pesticides levels from discharges (Srivastava et al., 2009). The adsorption based-technique is a promising process for pesticides removal because of its simplicity and the availability of various adsorbents (Tan et al., 2013).

Atrazine is widely utilized as a selective herbicide. It is applied to control annual broadleaf and grassy weeds for many crops all over the world. Atrazine belongs to the moderately persistent organic pollutants that is relatively mobile in soil (LeBaron et al., 2011). The half-life of atrazine in soil ranges from 14 to 108 days (Tuovinen et al.2015). Atrazine contamination has become a growing public concern because of its toxicity to the living organisms; atrazine may cause damages to the central nervous system, endocrine system, and immune system (Fan and Song 2014). The biological transformation and chemical retention are two major processes that affect the availability and the mobility of atrazine in the soil environment (Koskinen and Clay 1997).

Humic substances and clay minerals are considered the most essential soil constituents in the retention of soil-applied pesticides. Humic-clay complexes play considerable roles in controlling the retention and transport of hydrophobic organic pollutants in soils and sediments (Wang and Xing 2005). Natural clays are insignificant adsorbent of nonionic pesticides (Srivastava et al., 2009). It is well established that the uptake of nonpolar organic compounds from aqueous solution strongly corresponds with soil organic carbon content. In order to increase adsorption capacity of clay minerals, modification with quaternary ammonium surfactant has a high affinity towards most of hydrophobic organic compounds (Li et al., 2003; Ismadji et al., 2015).

Modified clays are used in many applications such as polymer nanocomposites, adsorbents of organic pollutants, gel formation, catalyst in organic synthesis, paints, cosmetics, petroleum industry, thixotropic fluids, etc. (DePaiva et al., 2008; Ahmed Gurses et al., 2011; Park et al., 2011). Furthermore, organoclays have been proposed for improving the controlled-release formulation efficacy and reducing the negative environmental impact of pesticides (Nir et al., 2006; Trigo et al., 2010) .

\footnotetext{
${ }^{1}$ Water Resources and Desert Land Division, Desert Research Center, Cairo, Egypt.

${ }^{2}$ Soil and Water Sciences Dept., Faculty of Agric., Alexandria University, Egypt.

*Corresponding Author: m.ali.osman@alexu.edu.eg

Received May 23, 2017, Accepted June 21, 2017
} 
Literature suggested that the herbicide adsorption capacity of organoclays is influenced by the nature of organic moiety that is applied for the modification process (DePaiva et al., 2008; Ismadji et al., 2015; Zhu et al., 2016). The objectives of this research were to examine the sorption/desorption characteristics of atrazine through equilibrium batch techniques on natural bentonite and organically modified bentonite clays and explore to contribute the methods of combating environmental pollution by atrazine.

\section{MATERIALS AND METHODS}

\section{Chemicals}

Analytical grade Atrazine (2-chloro-4-ethylamino-6isopropylamino-1,3,5-triazine) with purity $98.8 \%$ and humic acid (HA) powder were purchased from SigmaAldrich Co. Hexadecyltrimethylammonium bromide (HDTMA) obtained from Fluka with a reported purity 98\% (Table 1). All solvents used were high performance liquid chromatography (HPLC) grade from SigmaAldrich.

\section{Preparation of organo-bentonite}

The natural bentonite (bent.) was obtained from Egypt Company for Mining and Drilling Chemicals under the brand name (MB1100). The clay was used without performing any further purification. The CEC of the natural bentonite was $85.21 \mathrm{cmol} \mathrm{kg}^{-1}$ as determined by neutral normal ammonium acetate (Rhoades 1982). Humic-bentonite complex (Humic-bent.) was prepared at a ratio of 1:100 following the procedure of Wang and Xing (2005) and Li et al.,(2003). The syntheses of surfactant modified bentonite (HDTMA-bent.) was performed by exchanging the sodium on the surface of $\mathrm{Na}$-bentonite with cationic surfactant (HDTMA) at $100 \%$ of CEC according to $\mathrm{He}$ et al. (2010) and Oyanedel-Craver et al. (2007).

\section{Organoclay characterization}

Prior to the analysis, the materials were sieved and passed through a 170 mesh sieve. The Brunauer, Emmett and Teller [BET] surface area of clays was determined using $\mathrm{N}_{2}$ adsorption isotherm after degassed at $100{ }^{\circ} \mathrm{C}$ for $4 \mathrm{~h}$ under vacuum (BELSORP-mini II). Xray diffraction $(\mathrm{XRD})$ was performed on dried powder samples. The XRD patterns of natural bentonite and modified bentonite were recorded on a Philips diffractometer (PW 3710) using Co $\mathrm{K} \alpha$ radiation $(\lambda=$ $1.78897 \AA$ ) at $40 \mathrm{kV}$ and $35 \mathrm{~mA}$. The diffractogram was scanned from (20) 5 to 45 at scan rate $0.5^{\circ} \mathrm{min}^{-}$ ${ }^{1}$ (Rebecca 2004). The analysis of the infrared absorption of the clay samples were carried out in $\mathrm{KBr}$ pellets, using Jasco FTIR-4100 from wave number of 400 to $4000 \mathrm{~cm}^{-1}$ (Ma et al. 2010). Thermogravimetric analysis (TGA) was carried out for the clays using a Shimadzu TGA -50 instrument. The sample was heated in a platinum pan at temperature from 30 to $1000{ }^{\circ} \mathrm{C}$, at a rate of $10{ }^{\circ} \mathrm{C} \min ^{-1}$ in a following $\mathrm{N}_{2}$ atmosphere (Rebecca 2004). The percentages of $\mathrm{C}, \mathrm{H}$, and $\mathrm{N}$ in adsorbents were determined by Vario EL III Element Analyzer.

\section{Adsorption-desorption experiment}

Atrazine adsorption isotherms were determined in duplicate by using the batch equilibration technique (OECD. 2000). Stock solution was prepared by dissolving an appropriate amount of atrazine in methanol (HPLC grade) and kept in the freezer at $-20^{\circ} \mathrm{C}$. Stock concentrations and volumes transferred were intended to safeguard a methanol concentration of $0.2 \%$ by volume in the working solutions. The atrazine solutions are prepared directly in a background solution consists of $0.01 \mathrm{M} \mathrm{CaCl}$, besides $0.01 \% \mathrm{NaN}_{3}(\mathrm{pH}$ 7.20). For adsorption batch experiments, solid to solution ratios of $1: 100$ and 1:25 were applied for HDTMA-bent, and both of bentonite and Humicbentonite complex batches, respectively. Six initial concentrations $\left(\mathrm{C}_{\mathrm{i}}\right)$ ranged from 0.5 to $16 \mathrm{mg} \mathrm{L}^{-1}$ were used in Oak-ridge polypropylene tubes. The tubes were shaken (end-over-end) in the dark for $24 \mathrm{~h}$ at room temperature $\left(22 \pm 1^{\circ} \mathrm{C}\right)$. The $\mathrm{pH}$ values of the dispersions were measured after $24 \mathrm{~h}$ in separated tubes.

Table 1. Selected physicochemical properties of Atrazine and HDTMA Properties

Molecular structure<smiles>CCNc1nc(Cl)nc(NC(C)C)n1</smiles>

$\mathrm{C}_{8} \mathrm{H}_{14} \mathrm{ClN}_{5}$

Molecular formula

Molecular Weight

Water Solubility $\mathrm{pKa}^{*}$

( LeBaron et al. 2011)
$215.68 \mathrm{~g} \mathrm{~mole}^{-1}$

$33 \mathrm{mg} / \mathrm{L} @ 25^{\circ} \mathrm{C}$ $1.68 @ 20^{\circ} \mathrm{C}$

\section{HDTMA}

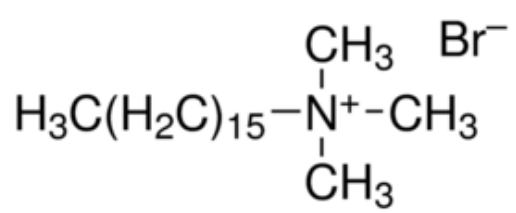

$\mathrm{C}_{19} \mathrm{H}_{42} \mathrm{NBr}$

$364.46 \mathrm{~g} \mathrm{~mole}^{-1}$

$13 \mathrm{~g} / \mathrm{L} @ 20^{\circ} \mathrm{C}$ 
The aqueous phase was separated by centrifugation at $5000 \mathrm{rpm}$ for $15 \mathrm{~min}$. Subsequently, $10-\mathrm{ml}$ aliquot of supernatant was withdrawn directly from the centrifuge tube and filtered through a disposable $0.45-\mu \mathrm{m}$ PTFE syringe filter. A control was conducted without sorbents, in the same way, to determine the amount of solute sorbed by the used tube. Blank was prepared with sorbents and background solution for background correction. The amount of atrazine adsorbed (S) was calculated based on the mass balance between the initial and the equilibrium atrazine concentrations in solution. $\mathrm{S}=\mathrm{V}\left(\mathrm{C}_{\mathrm{i}}-\mathrm{C}_{\mathrm{e}}\right) / \mathrm{M}$ where $\mathrm{M}$ is the mass of adsorbent $(\mathrm{g})$ and $\mathrm{V}$ is the solution volume $(\mathrm{ml})$. Desorption procedure was performed immediately after adsorption step from the highest three equilibrium points of the adsorption isotherms. Desorption's cycles were executed by replacing $50 \%$ of the supernatant with a fresh (sorbatefree) background solution. The tubes were re-dispersed by vortex mixer and shaked under the same conditions of the applied adsorption experiments. Each desorption cycle was repeated six times consecutively.

\section{HPLC analysis}

Atrazine in the supernatant solution was determined using Thermo Scientific-Surveyor plus HPLC System equipped with UV/Vis plus detector at a wavelength of $220 \mathrm{~nm}$. A Hypersil GOLD, $5 \mu \mathrm{m}$ reverse phase column was used with a length of $150 \mathrm{~mm}$ and an inner diameter of $4.6 \mathrm{~mm}$. The HPLC analyses were carried out using an isocratic elution mode with a mobile phase constituted by $55 \%(\mathrm{v} / \mathrm{v})$ water contains $5 \%$ methanol and $45 \%(\mathrm{v} / \mathrm{v})$ methanol. The analyses were performed at a flow rate of $1.0 \mathrm{ml} \mathrm{min}{ }^{-1}$. The injection volume was $20 \mu \mathrm{l}$. Under these analytical conditions, an atrazine retention time was $7.8 \mathrm{~min}$.

\section{Data analysis}

Two mathematical models were used to describe experimental data of adsorption isotherms (Selim and Zhu 2005; McDonald et al., 2013). A simple linear model: $\mathrm{S}=\mathrm{K}_{\mathrm{d}} \mathrm{C}_{\mathrm{e}}$, where $\mathrm{S}$ is the adsorbed amount per unit mass $\left(\mathrm{mg} \mathrm{kg}^{-1}\right), \mathrm{C}_{\mathrm{e}}$ is the equilibrium concentration of the solute in the bulk solution $\left(\mathrm{mg} \mathrm{L}^{-1}\right)$, and $\mathrm{K}_{\mathrm{d}}$ is a distribution coefficient $\left(\mathrm{L} \mathrm{kg}^{-1}\right)$. Freundlich isotherm model: $\mathrm{S}=\mathrm{K}_{\mathrm{f}} \mathrm{C}^{\mathrm{N}}$, where $\mathrm{K}_{\mathrm{f}}$ is a Freundlich capacity coefficient $\left(\mathrm{mg} \mathrm{kg}^{-1}\right) /\left(\mathrm{mg} \mathrm{L}^{-1}\right)^{\mathrm{N}}$ and $\mathrm{N}$ is the adsorption intensity describes the isotherm curvature (dimensionless). The organic carbon-normalized distribution coefficients $\left(\mathrm{K}_{\mathrm{OC}}\right)$ were calculated as: $\mathrm{K}_{\mathrm{oc}}=$ $100 \times \mathrm{K}_{\mathrm{d}} / \mathrm{OC}$, where OC is the organic carbon content in percentage. The percentage of removal efficiency $(\mathrm{R})$ was calculated as: $\mathrm{R} \%=\left(\mathrm{C}_{\mathrm{i}}-\mathrm{C}_{\mathrm{e}}\right) / \mathrm{C}_{\mathrm{e}} \times 100$. The ratios of the Freundlich exponents for desorption and adsorption $\left(\mathrm{N}_{\text {des }} / \mathrm{N}\right)$ refers to Hysteresis Index (HI). Lower index values show increased difficulty of the sorbed analyte to be desorbed from the adsorbent (Lima et al, 2010; Hedia and Al-Aswad 2016). Observed desorption data has been fitted to first-order kinetic model as: $\mathrm{S}_{\mathrm{t}} / \mathrm{S}_{\mathrm{o}}=\mathrm{e}^{-\mathrm{k}} 1^{\mathrm{t}}$ where $\mathrm{S}_{\mathrm{o}}$ is the amount initially adsorbed $\left(\mathrm{g} \mathrm{kg}^{-1}\right), \mathrm{S}_{\mathrm{t}}$ is the amount desorbed at different times $\left(\mathrm{g} \mathrm{kg}^{-1}\right)$, and $\mathrm{k}_{1}$ is the rate constant for the first order reaction $\left(h^{-1}\right)$ (Daneshvar et al. 2017).

\section{RERSULTS AND DISCUSSION}

\section{Physicochemical properties of adsorbents}

The Egyptian natural bentonite was characterized by CEC of $85.21 \mathrm{cmol} \mathrm{kg}^{-1}$ and by particle size distribution consists of $24.32 \%$ sand, $3.45 \%$ silt, and $72.23 \%$ clay. Physicochemical properties of bentonite, surfactant modified bentonite, and humic bentonite complex are presented in Table 2. Natural bentonite was alkaline in nature, $\mathrm{pH}$ value of 10 , while intercalation of organic substances resulted in a decrease of the $\mathrm{pH}$ values to slight alkaline. Based on elemental analysis, the carbon and nitrogen content of bentonite was negligible and was increased by organic modification. The carbon content reached $0.82 \%$ in Humic-bent and $15.28 \%$ in HDTMA-bent. The ratio of C/N for HDTMA-bent was 16.44. This value is close to the theoretical estimation of $\mathrm{C} / \mathrm{N}$ ratio which was computed as 16.29 . This ratio demonstrates that the modification of natural bentonite by HDTMA was effectively realized (Erdem et al., 2010). The BET surface areas and total pore volume of natural bentonite were $44.77 \mathrm{~m}^{2} \mathrm{~g}^{-1}$ and $0.062 \mathrm{~cm}^{3} \mathrm{~g}^{-1}$, respectively, which is consistent with Mockovčiaková et al., (2009) and Jiang et al.,(2002). A significant decrease of the surface area and pore volume was observed upon organic modification. In Humic bentonite complex, low surface area probably attributed to coating the outer surface of bentonite particles with humic acid.

Table 2. Characteristics of natural bentonite and modified organo-bentonite

\begin{tabular}{lccccccc}
\hline \multirow{2}{*}{ Sorbent } & \multirow{2}{*}{$\mathbf{p H}$} & Surface area & Pore volume & \multicolumn{2}{c}{ Elemental composition (\%) } & \multicolumn{1}{c}{$\mathbf{d}(\mathbf{0 0 1})$} \\
\cline { 3 - 8 } & & $\mathbf{m}^{\mathbf{2}} \mathbf{g}^{-\mathbf{1}}$ & $\mathbf{c m}^{\mathbf{3}} \mathbf{g}^{-\mathbf{1}}$ & $\mathbf{C}$ & $\mathbf{H}$ & $\mathbf{N}$ & $\mathbf{\AA}$ \\
\hline Bentonite & 10.0 & 44.77 & 0.062 & 0.32 & 1.27 & Nil & 14.05 \\
Humic-bent. & 8.16 & 5.51 & 0.016 & 0.82 & 1.89 & Nil & 15.99 \\
HDTMA-bent. & 7.90 & 5.68 & 0.022 & 15.28 & 3.23 & 0.91 & 21.70 \\
\hline
\end{tabular}




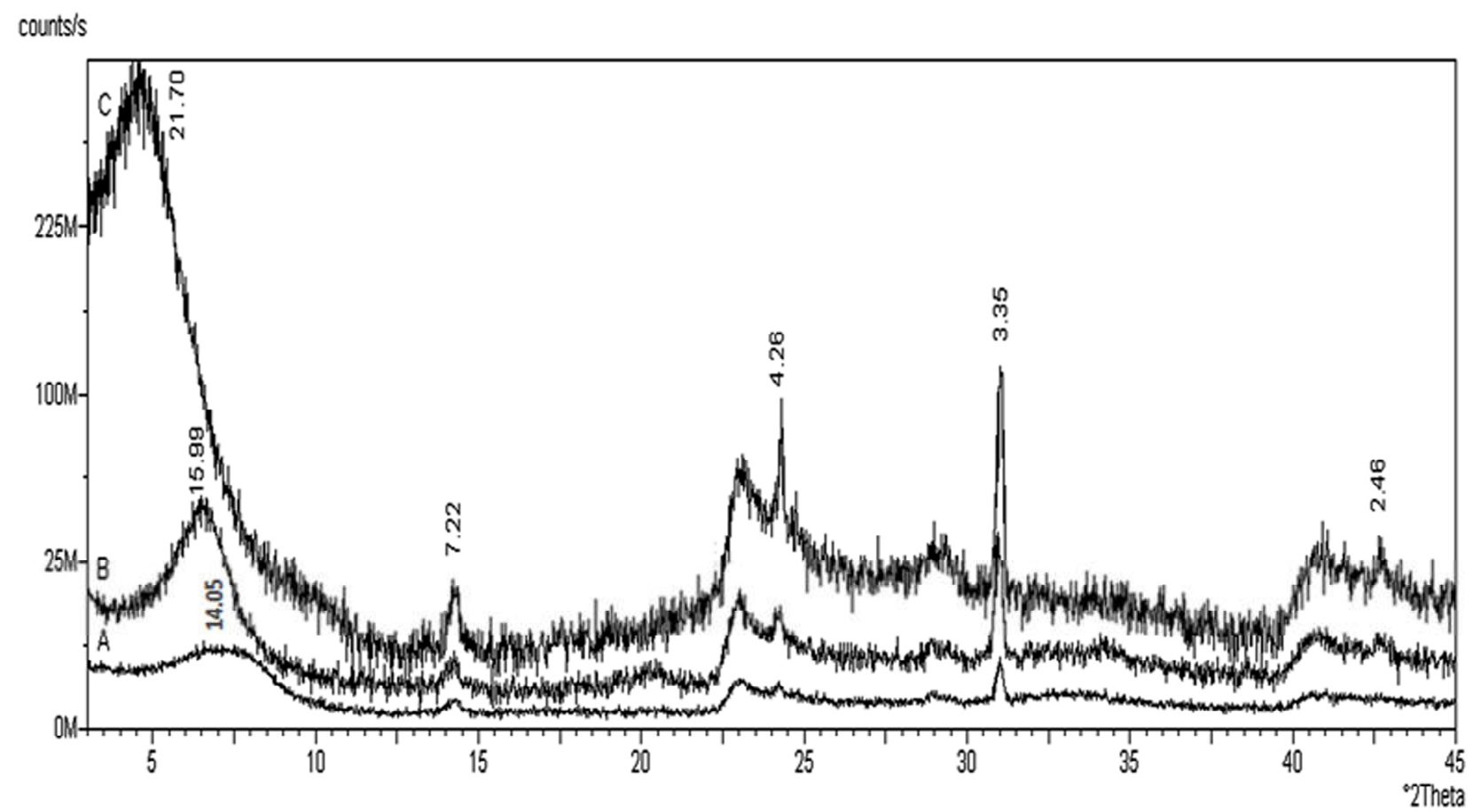

Figure 1. XRD chromatograms for natural and modified clays: (A) Natural bentonite, (B) Humic-bentonite, (C) HDTMA-bentonite

Ksiezopolska and Pazur (2011) reported that the specific surface area of bentonite and illite reduced after complexion with humic acids at all $\mathrm{pH}$ values as a result of lodged humic acid in the active sites on clays and making the surface of the complex hydrophobic. Whereas, in surfactant modified bentonite the interparticle pores are covered and clogging of the interlayer space by HDTMA molecules prevented the $\mathrm{N}_{2}$ access to the inner surface of material (He et al., 2010; Erdem et al., 2010; Emam 2013).

\section{$\mathrm{X}$-Ray Diffraction analysis}

XRD diffractograms of bentonite and its modifications are presented in Figure 1. XRD pattern of natural bentonite approved montmorillonite as the dominant mineral phase and quartz as the main impurity mineral with traces of kaolinite. The modification of bentonite with organic substances, through their incorporation into interlayer space, leads to expansion of bentonite. It was confirmed by a decrease in the $2 \theta$ values and increment basal spacing (d-value) for modified bentonite (Table 2). Intercalation of humic acid and HDTMA in the interlayers of bentonite displayed a different effect on $\mathrm{d}_{001}$-spacing value. The $\mathrm{d}$ value for natural bentonite corresponded to $14.05 \AA$ expanded to $21.70 \AA$ for HDTMA-bent which is in agreement with other studies (Erdem et al., 2010 and Dutta and Singh 2015). The basal spacing expansion is owing to the interpenetration of HDTMA ion into the layers of bentonite. It was demonstrated that the structural configuration of alkyl chains, in the interlamellar space, is pseudotrimolecular layer which is comprised of three alkyl chains in which the nonpolar chain ends are moved one above the other by the formation of kinks (Nuntiya et al., 2008). Conversely, Humic-bent. exhibited a small expansion at d-value of $15.99 \mathrm{~A}^{0}$, which indicates that humic acid was associated meanly with the external surfaces of the bentonite due to the large size of humic acid molecule (Li et al., 2003; Sun et al., 2016).

\section{Fourier transform infrared (FTIR)}

The FTIR spectrum specifies the physisorption and chemisorption of the organic modifier onto the bentonite due to the existence, shift or disappearance of the peaks of functional groups. FTIR spectra of natural bentonite and modified bentonites were examined and compared to each other over the range $4000-400 \mathrm{~cm}^{-1}$ (Figure 2). The bands at $3696 \mathrm{~cm}^{-1}$ and $3624 \mathrm{~cm}^{-1}$ was assigned to $\mathrm{Al}-\mathrm{Mg}-\mathrm{OH}$ stretching and $\mathrm{Al}-\mathrm{Al}-\mathrm{OH}$ stretching respectively. Al-Al-OH bending vibrations band at 916 $\mathrm{cm}^{-1}$ and $\mathrm{Al}-\mathrm{Fe}-\mathrm{OH}$ bending vibrations at $795 \mathrm{~cm}^{-1}$ were typical of bentonite clays. Consequently, the bentonite utilized in the present study was rich in aluminum and contained a portion of magnesium and iron too (Sikdar et al., 2008). The Si-O stretching band was seen at 1031 
$\mathrm{cm}^{-1}$, and the band at $525 \mathrm{~cm}^{-1}$ was allotted to the Si-O bending vibration. A doublet at 780 and $795 \mathrm{~cm}^{-1}$ demonstrated the presence of quartz in the bentonite. A broad band at $3450-3440 \mathrm{~cm}^{-1}$ region was allocated to the $-\mathrm{OH}$ stretching vibration, whereas band at $1637 \mathrm{~cm}^{-1}$ was assigned to the $-\mathrm{OH}$ bending vibrations of water adsorbed in the bentonite (Dutta and Singh 2015; Shehata et al., 2016).

The spectra of pure humic acid distinguished with peaks at 1740,1640 , and $1260 \mathrm{~cm}^{-1}$ were attributed to $\mathrm{C}=\mathrm{O}$ stretching vibration of the carboxyl group, $\mathrm{C}=\mathrm{C}$ stretching vibrations of aromatic structures and $\mathrm{C}-\mathrm{O}$ stretching vibration, respectively (data not shown). Interactions of humic acid with bentonite have occurred leading to the absence of peak 1740 and $1260 \mathrm{~cm}^{-1}$ or diminished considerably, while the $\mathrm{C}=\mathrm{C}$ of the aromatic structures peak in the region of $1640 \mathrm{~cm}^{-1}$ was overlaid to $-\mathrm{OH}$ bending model of adsorbed water (Sun et al., 2016). Generally, Humic-bentonite complex did not show any distinct peak than bentonite (Figure 2). Specifically, there was a slight shift in the position of bands after modification with cationic surfactants. Furthermore, sorbed water content declined with the intercalation of HDTMA which resulted from the substitution of hydrated cations by HDTMA+ ions. A couple of peaks at 2924 and $2851 \mathrm{~cm}^{-1}$ can be relegated to the symmetric and asymmetric stretching $-\mathrm{CH}_{2}$ vibrations of methylene groups and their bending vibrations at 1473 and $1408 \mathrm{~cm}^{-1}$ were only observed on HDTMA-bentonite (Hongping et al., 2004; Ma et al., 2010).

\section{Thermogravimetric analysis (TGA)}

TGA analysis was used to determine the thermal stability of natural bentonite and modified bentonite. As shown in Figure 3, unmodified bentonite shows two stages of weight losses. The first stage at $39-136{ }^{\circ} \mathrm{C}$ leads to weight loss about $11.37 \%$, which corresponds to surface-adsorbed water and water associated with the interlayer cations. The second stage at $458-591{ }^{\circ} \mathrm{C}$ included weight loss of $3.14 \%$ which is related to structural water arising from dehydroxylation of the clay layers (Xi et al., 2004; Huskic et al., 2009; Mallakpour and Dinari 2013).

Regularly, bentonite does not experience thermally incited changes in the temperature range of $170-450{ }^{\circ} \mathrm{C}$, subsequently the weight loss in this temperature range should be attributed to the decomposition of the surfactant. In this respect, the occurrence of organic cations increases the number of decomposition steps for organo-clay. Several studies have documented that the decomposition of an organo-clays takes place in four steps: water desorption, dehydration, desurfactant, and dehydroxylation of the organoclays (Xi et al., 2005; Mallakpour and Dinari 2013).

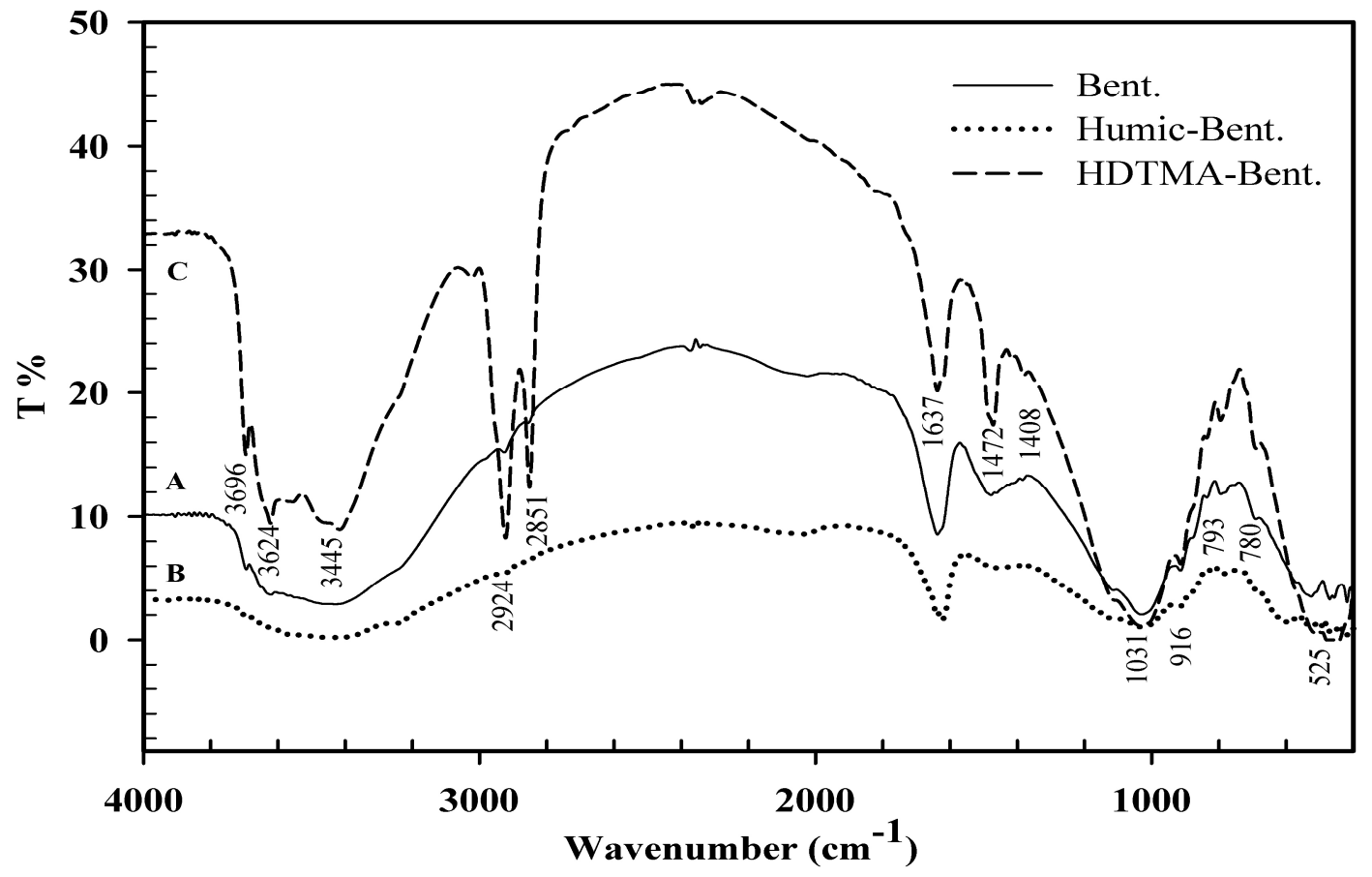

Figure 2. FTIR spectra of natural and modified clays: (A) Natural bentonite, (B) Humic-bentonite, (C) HDTMA-bentonite 


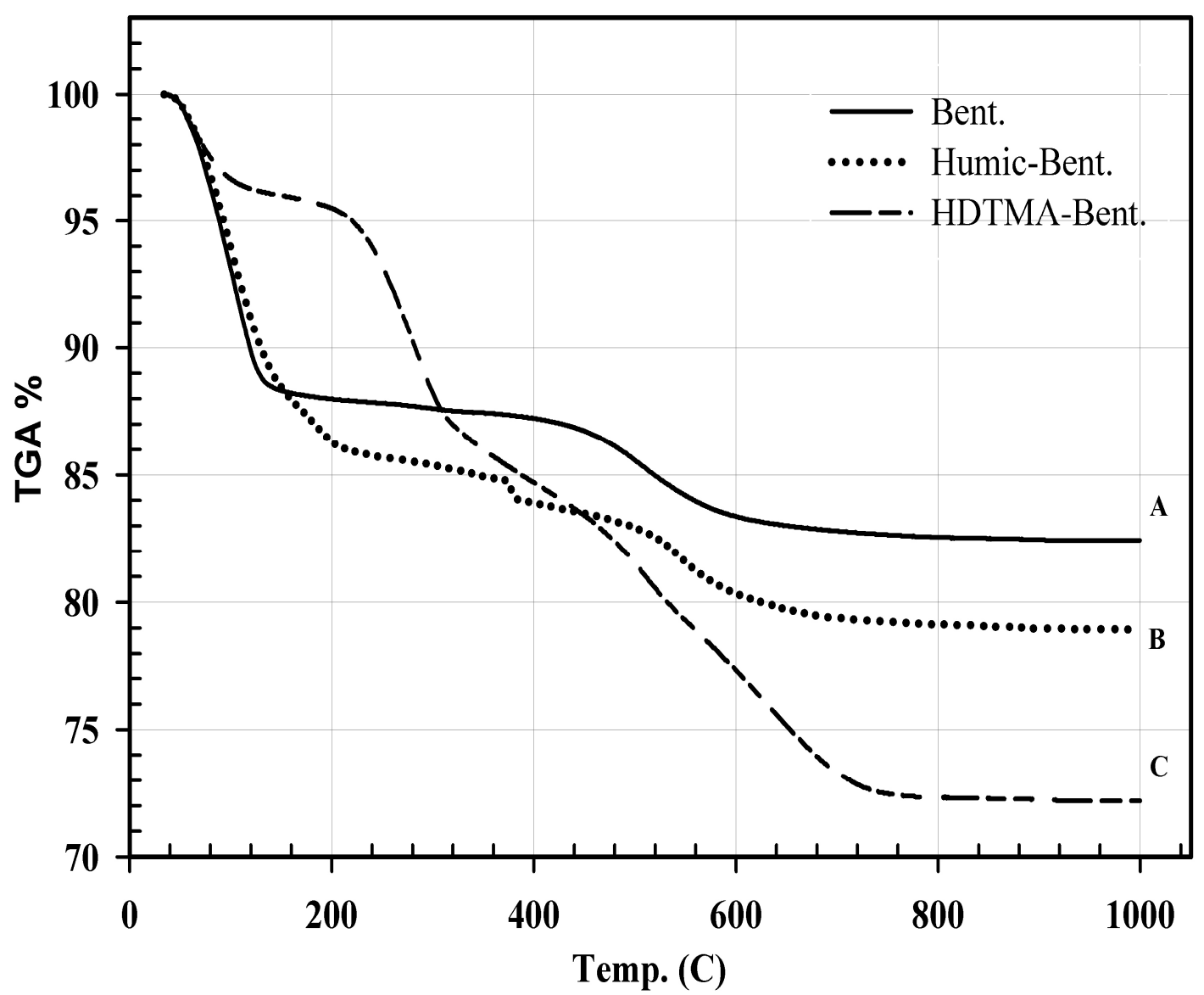

Figure 3. TGA curves of natural and modified clays: (A) Natural bentonite, (B) Humic-bentonite, (C) HDTMA-bentonite

In the case of HDTMA, the first two steps of decomposition involved the dehydration of the interparticle adsorbed and interlayer water which occurs between 49 and $127{ }^{\circ} \mathrm{C}$ with weight loss of approximately $3.46 \%$ (Figure 3 ). In comparing with the TGA of the raw bentonite, the HDTMA-bent. exhibited less weight loss during dehydration. The shift to the lower temperature indicates the existence of weakly bound physioadsorbed water and confirmed the replacement with surfactant between bentonite layers. A downward shift of similar magnitude was also reported by Yapar (2009). The third step attributed to desurfactant is split into two stages; the first stage is occurred around $198-306{ }^{\circ} \mathrm{C}$ with $8.16 \%$ weight loss is corresponding to the decomposition of some HDTMA cations on the surface of bentonite. The second stage at $306-449{ }^{\circ} \mathrm{C}$ with $4.86 \%$ weight loss is assigned to the decomposition of some HDTMA cations between the layers of bentonite (Tiwari et al., 2008; Erdem et al., 2010). The fourth step is referring to the loss of dehydroxylation of the structural $\mathrm{OH}$ units of the bentonite at $449-745{ }^{\circ} \mathrm{C}(13 \%$ weight loss $)$. These results emphasize that the surfactants has been located on the surface and entered into the interlayer spacing of bentonite. Many reviews mentioned that the intercalation of surfactant into the interlayer space increased the thermal stability of the surfactant (DePaiva et al., 2008; Ismadji et al., 2015).

Figure 3 displays the TGA for Humic-bent where the first weight loss of $13.81 \%$ was observed at 35 to $205^{\circ} \mathrm{C}$ and was related to the evaporation of bound water from humic acid beside humic-bent complexes. The second weight loss $(1.99 \%)$ was observed between 205 and $377^{\circ} \mathrm{C}$ corresponds to humic acid decomposition. Decline of this ratio was a result of reduced carbon content in the elemental analysis. The third weight loss (3.24\%) located a 428 and $599^{\circ} \mathrm{C}$ relates mainly to the dehydroxylation of the clay sheets (Sun et al., 2016).

\section{Adsorption-desorption isotherms}

The adsorption parameters of atrazine on natural bentonite and modified bentonite clays are shown in (Table 3). The sorption isotherm data is fitted well the 
linear and Freundlich adsorption isotherms with correlation coefficients $\left(\mathrm{R}^{2}\right)$ which higher than 0.95 . The natural bentonite exhibited low sorption affinity to atrazine with distribution coefficient of $3.07 \pm 0.04 \mathrm{~L}$ $\mathrm{kg}^{-1}$ and removal efficiency of $10.98 \%$. Herwig et al., (2001) reported a $K_{d}$ value of $3.27 \mathrm{~L} \mathrm{~kg}^{-1}$ for $\mathrm{Na}-$ montmorillonite and the atrazine intercalate into the external surface by the relatively weak physical forces. The experimental results indicate the significant increase of bentonite affinity for atrazine due to the modification of natural bentonite with HDTMA. Specifically, the modified HDTMA-bentonite exhibited the maximum removal efficiency of $66.48 \%$ with distribution coefficient of $197.97 \pm 0.77 \mathrm{~L} \mathrm{~kg}^{-1}$. On the other hand, the modified humic-bentonite exhibited low sorption affinity to atrazine with distribution coefficient of $2.15 \pm$ $0.14 \mathrm{~L} \mathrm{~kg}^{-1}$ and removal efficiency of $7.38 \%$. Our results on the contrast with those of Abate et al., (2004) who found that humic substance enhanced adsorption of atrazine and some of its metabolites in soil. This difference can be attributed to $\mathrm{pH}$, which slightly alkaline (8.16) (Table 2). Tan et al., (2013) reported that the amounts of adsorbed atrazine decreased with increasing $\mathrm{pH}$ and the highest adsorption observed at $\mathrm{pH}$ equal to 2. Davies and Jabeen (2003) demonstrated that atrazine is adsorbed on humic acid by interacting with the $\mathrm{C}=\mathrm{O}$ and $-\mathrm{OH}$ groups by hydrogen bonding and/or by protonation.

The sorption isotherm linearity of the natural bentonite and HDTMA-bentonite is confirmed by the values of the dimensionless Freundlich constant $(\mathrm{N})$ which is found to be close to the unity. These values of $\mathrm{N}$ indicate a constant relative affinity of the solute molecules by the adsorbent, C-type isotherm (Table 3). This implies that non-specific interactions occur amongst solute and adsorbent (Abate and Masini 2005). HDTMA-bentonite contain paraffin-like layer of organic phase in the interlayer of the clay lattice, which acts as the partition medium for the sorption of atrazine. Even at higher solute concentrations, there were enough sites available for the atrazine adsorption. The deviation of linearity observed in Humic-bentonite $(\mathrm{N}=0.79)$ proposing L-type isotherms that is characterized by the decrease in the adsorption at higher aqueous concentrations of the solute. This demonstrates greater competition for adsorption sites which become limited as solute concentration in solution increased (Dutta and Singh 2015).

\section{Atrazine Desorption and Hysteresis}

Results of the desorption experiment (Table 4) suggest that a fraction of the sorbed atrazine was predisposed desorption, and the percentage of atrazine released from successive desorption steps was dependent on the type of adsorbent. Atrazine desorption data fitted well to the Freundlich isotherm with $\mathrm{R}^{2}$ greater than 0.95 .

The desorption-Freundlich constant $\left(\mathrm{N}_{\mathrm{des}}\right)$ values of the natural bentonite and the humic-bentonite were lower than the corresponding $\mathrm{N}$ constants suggesting that the rate of desorption was slower than the rate of adsorption and hysteresis was observed (see Table 3). The $\mathrm{N}_{\text {des }}$ values of bentonite and Humic-bent isotherms were less than unity, indicating an L-type isotherm. Humic acid was a source of increased hysteresis in humic-bentonite complexes ( $\mathrm{Li}$ et al., 2003). On the other hand, desorption process of atrazine onto HDTMA-bentonite is reversible, as shown in Figure 4, which shows desorption curves overlapping the adsorption ones.

Hysteresis Index (HI) is manifested by an increase in the difference between the adsorption and desorption isotherm slopes demonstrating chemically non-ideal behavior (rate-limited desorption). HI is negative when it is more than one, while it is positive when it is less than one (Dutta and Singh 2015). In the case of HDTMA-bentonite, the HI value is about 1 indicating that the interaction is based on a partitioning mechanism. Such a behavior reveals that the surfactant modified bentonite has potential application in controlrelease formulation of atrazine (Trigo et al., 2010). Moreover, another potential application is the improvement of stationary phases for chromatographic columns that could be eluted utilizing water as mobile phase (Abate and Masini 2005; Dutta and Singh 2015).

The hysteresis of atrazine adsorption-desorption isotherms on natural bentonite and modified bentonite clays are shown in Figure 4. Results revealed that the actual atrazine concentrations in solution after desorption were considerably less than the equilibrium concentrations in the case of natural bentonite and humic-bentonite isotherms. The nonsingularity is clearly observed for bentonite and humic-bentonite isotherms whereas HDTMA-bentonite exhibited no significant hysteresis (Figure 4). Such hysteresis is an indicative of the nonequilibrium adsorption of atrazine on the natural bentonite and the modified humic-bentonite. The percentage of atrazine released from successive desorption steps was dependent on the type of adsorbent. Celis et al., (1997) stated that Atrazine was less hysteretic for bentonite than for humic acid, demonstrating that atrazine desorbs more difficultly from organic substances than from clay minerals owing to the contribution of hydrophobic interactions with humic acid. 

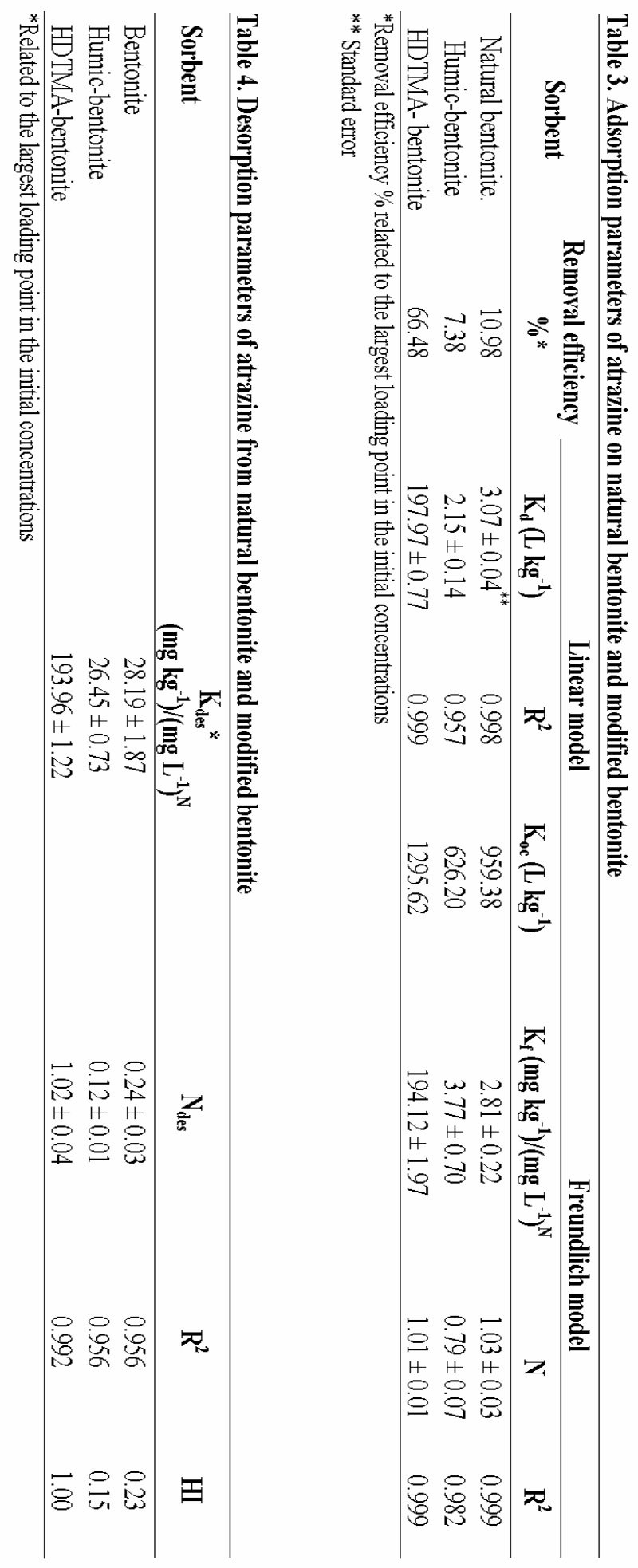

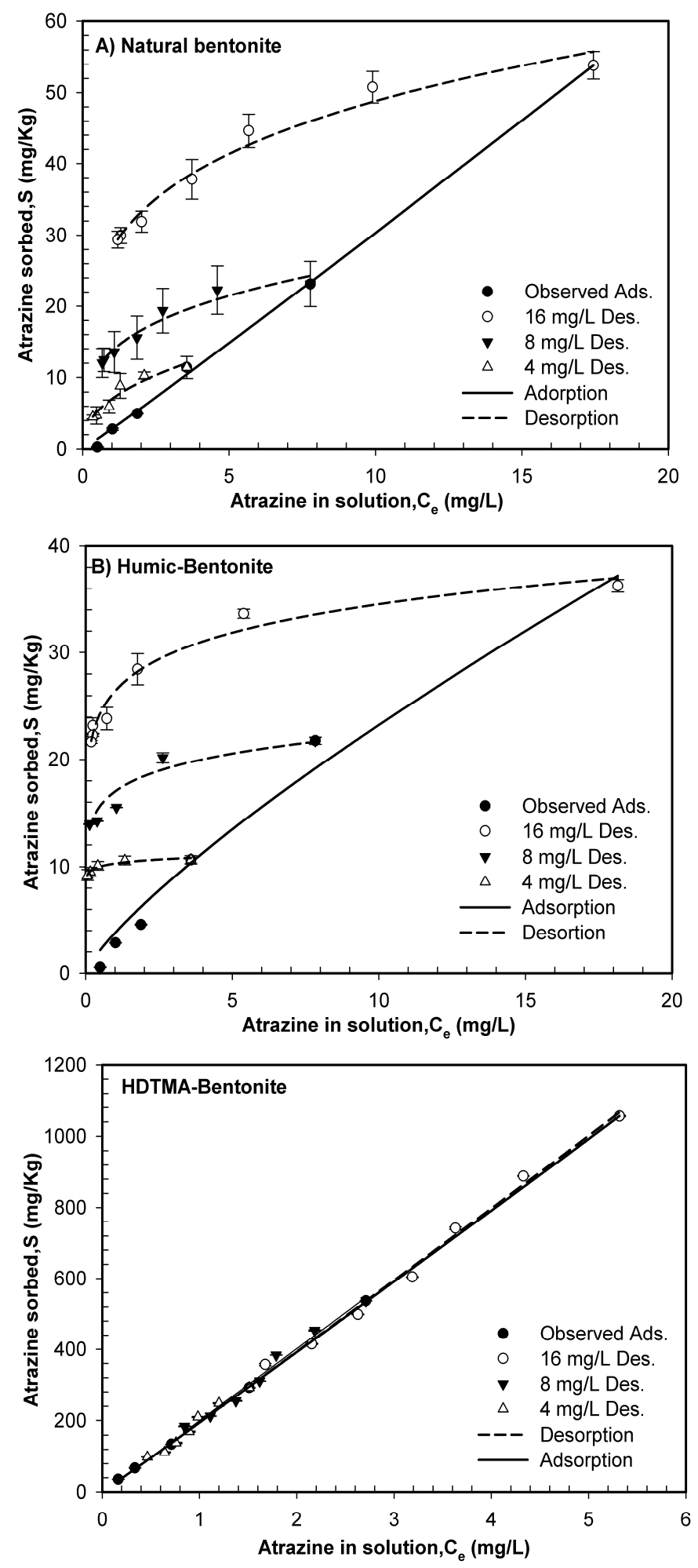

Figure 4. Adsorption and desorption of atrazine for natural and modified clays: (A) Natural bentonite, (B) Humic-Bentonite, (C) HDTMA-Bentonite. The solid and dashed curves are the fitted Freundlich isotherms model for adsorption and desorption, respectively while the symbols are the measured data 

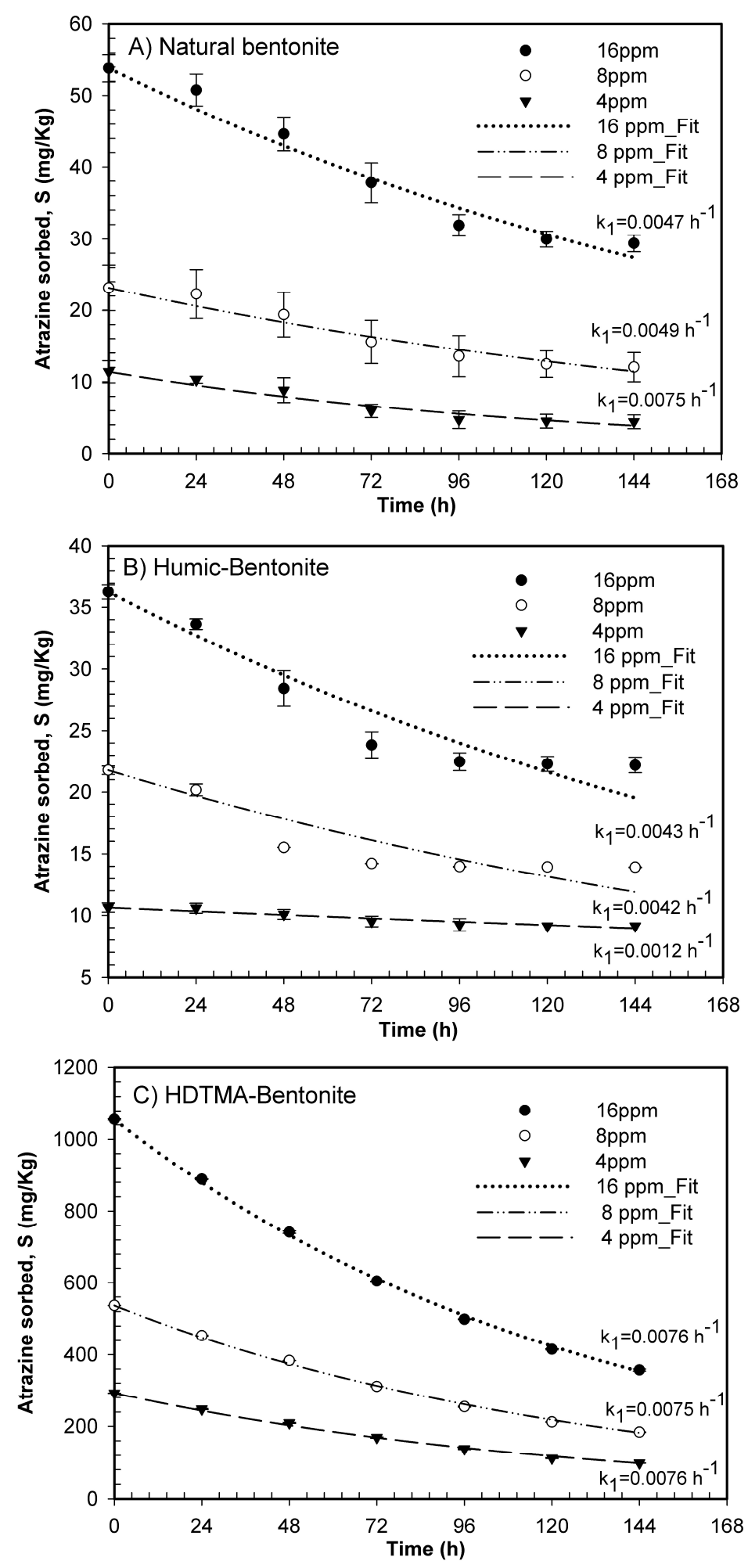

Figure 5. Kinetic of atrazine desorption for natural and modified clays: (A) Natural bentonite, (B) HumicBentonite, (C) HDTMA-Bentonite. The symbols are the measured data while the dashed curves are the predicted first order reaction 


\section{Desorption kinetic}

The kinetic of atrazine desorption from natural bentonite and modified bentonite clays are plotted in Figure 5. The percentages of desorbed atrazine after 144 $\mathrm{h}$ from the natural bentonite were $58.6 \%, 41.4 \%$, and $40.8 \%$ for initial atrazine concentrations, $\mathrm{C}_{\mathrm{o}}$, of $4.0 \mathrm{mg}$ $\mathrm{L}^{-1}, 8.0 \mathrm{mg} \mathrm{L}^{-1}$, and $16.0 \mathrm{mg} \mathrm{L}^{-1}$, respectively, whereas humic-bentonite exhibited the lowest released atrazine and the respective percentages were $13.3 \%, 35.9 \%$, and $36.1 \%$. However, desorption experimental time was extended to $144 \mathrm{~h}$, there was no significant atrazine release from natural bentonite and humic- bentonite clays after $96 \mathrm{~h}$. This limited kinetic of atrazine desorption can be attributed to the low sorption capacity of the natural bentonite and the modified humicbentonite. On the other hand, the modified HDTMAbentonite exhibited a time-dependent behavior for atrazine release. Specifically, a continuous decrease of the sorbed atrazine was observed during desorption experimental time $(144 \mathrm{~h})$. The HDTMA-bentonite showed the highest desorption of atrazine where the percentages of desorbed atrazine after 144 hours were $66.3 \%, 65.7 \%$, and $66.2 \%$ with total average of 66.1 $\%$. Desorption kinetic data was seem fitted with first order kinetic reaction model with $\mathrm{R}^{2}$ equal to $0.96,0.87$, 0.99 for bentonite, humic- bentonite, and HDTMAbentonite respectively. Specifically in bentonite average estimated $\mathrm{k}_{1}$ was $0.0057 \pm 0.0007 \mathrm{~h}^{-1}$ decreased to $0.0032 \pm 0.0008 \mathrm{~h}^{-1}$ in humic-bentonite, whereas increased to $0.0076 \pm 0.00003 \mathrm{~h}^{-1}$ in HDTMA- bentonite (Figure 5).

\section{CONCLUSIONS}

Equilibrium batch experiments were performed to assess the sorption/desorption of atrazine on natural bentonite, humic-bentonite complex, and HDTMAmodified bentonite. Characterization of natural and modified clays indicated the decrease in the $\mathrm{pH}$ and the surface area values of the modified bentonite. FTIR spectrum specified the similarity of natural bentonite and humic-bentonite peaks. Whereas HDTMAmodified bentonite exhibited a slight shift in the position of bands. Results revealed the low affinity of atrazine on natural bentonite and humic-bentonite complex with removal efficiencies of 10.98 and $7.38 \%$, respectively. The HDTMA-modified bentonite exhibited the highest sorption affinity with removal efficiency of $66.48 \%$ and distribution coefficient of $197.97 \pm 0.77 \mathrm{~L} \mathrm{~kg}^{-1}$. Natural bentonite and humic-bentonite clearly exhibited nonsingularity of sorption/desorption isotherms. The modified HDTMA-bentonite exhibited a limited hysteresis with a time-dependent release of atrazine. Atrazine desorption data was successfully fitted with the first order kinetic reaction model confirmed with the statistical criteria of the goodness-of-fit. These results show the potential use of HDTMA-bentonite as a carrier for atrazine controlled release formulations as well as its application for environmental remediation.

\section{REFERENCES}

Abate, G. and J. C. Masini. 2005. Sorption of atrazine, propazine, deethylatrazine, deisopropylatrazine and hydroxyatrazine onto organovermiculite. J. Brazilian Chem. Soc. 16(5): 936-943.

Abate, G., J. C. Penteado, j. D. Cuzzi, G. C. Vitti, J. Lichtig and J. C. Masini. 2004. Influence of humic acid on adsorption and desorption of atrazine, hydroxyatrazine, deethylatrazine, and deisopropylatrazine onto clay-rich soil sample. J. Agric. Food Chem. 52: 6747-6754.

Ahmet Gurses, M. Ejder-Korucu and S. Karaca. 2011. clayorganoclay and organoclay polymer nanocomposites. In: J. P. Humphrey and D. E. Boyd eds. Clay: Types, Properties and Uses. pp. 155-191. Nova Science Publishers, Inc.

Cara, I. G. and G. Jităreanu. 2015. Application of Low-Cost Adsorbents for Pesticide Removal. Bulletin of the University of Agricultural Sciences \& Veterinary Medicine Cluj-Napoca. Veterinary Medicine. 72(1).

Celis, R., J. Cornejo, M. C. Hermosin and W. C. Koskinen. 1997. Sorption-desorption of atrazine and simazine by model Soil colloidal Components. Soil Sci. Soc. Am. J. 61: 436-443.

Daneshvar, E., A. Vazirzadeh, A. Niazi, M. Kousha, M. Naushad and A. Bhatnagar. 2017. Desorption of Methylene blue dye from brown macroalga: Effects of operating parameters, isotherm study and kinetic modeling. Journal of Cleaner Production. 152: 443-453.

Davies, J. E. D. and N. Jabeen. 2003. The adsorption of herbicides and pesticides on clay minerals and soils. Part 2. Atrazine. J. inclusion phenomena and macrocyclic chem. 46(1): 57-64.

DePaiva, L. B., A. R. Morales and F. R. V. Díaz. 2008. Organoclays: Properties, preparation and applications. Applied Clay Sci. 42: 8-24.

Dutta, A. and N. Singh. 2015. Surfactant-modified bentonite clays: preparation, characterization, and atrazine removal. Environ. Sci. Pollut. Res. 22(5): 3876-3885.

Emam, E. A. 2013. Modified activated carbon and bentonite used to adsorb petroleum hydrocarbons emulsified in aqueous solution. Am J Environ Prot. 2(6): 161-169.

Erdem, B., A. S. Ozcan and A. Ozcan. 2010. Preparation of HDTMA-bentonite: Characterization studies and its adsorption behavior toward dibenzofuran. Surface and Interface Analysis. 42(6-7): 1351-1356.

Fan, X. and F. Song. 2014. Bioremediation of atrazine: recent advances and promises. Journal of soils and sediments. 14(10): 1727-1737. 
He, H., Y. Ma, J. Zhu, P. Yuan and Y. Qing. 2010. Organoclays prepared from montmorillonites with different cation exchange capacity and surfactant configuration. Applied Clay Sci. 48(1-2): 67-72.

Hedia, R. M. and A. F. El-Aswad. 2016. Spinosad Adsorption on Humic and Clay Constituents of Lacustrine Egyptian Soils and Its Leaching Potential. Alexandria Science Exchange. 37(3): 458.

Herwig, U., E. Klumpp, H.-D. Narres and M. J. Schwuger. 2001. Physicochemical interactions between atrazine and clay minerals. Applied Clay Science. 18(5): 211-222.

Hongping, H., F. L. Ray and Z. Jianxi. 2004. Infrared study of HDTMA+ intercalated montmorillonite. Spectrochimica Acta Part A: Molecular and Biomolecular Spectroscopy. 60(12): 2853-2859.

Huskić, M., E. Žagar, M. Žigon, I. Brnardić, J. Macan and M. Ivanković. 2009. Modification of montmorillonite by cationic polyesters. Applied Clay Sci. 43(3): 420-424.

Ismadji, S., F. E. Soetaredjo and A. Ayucitra. 2015. Natural clay minerals as environmental cleaning agents Clay Materials for Environmental Remediation. pp. 5-37. Springer.

Jiang, J.-Q., C. Cooper and S. Ouki. 2002. Comparison of modified montmorillonite adsorbents: part I: preparation, characterization and phenol adsorption. Chemosphere. 47(7): 711-716.

Koskinen, W. and S. Clay. 1997. Factors affecting atrazine fate in north central US soils Reviews of environmental contamination and toxicology. pp. 117-165. Springer.

Ksiezopolska, A. and M. Pazur. 2011. Surface properties of bentonite and illite complexes with humus acids. Clay Minerals. 46(1): 149-156.

LeBaron, H. M., J. Mc Farland and O. Burnside. 2011. The triazine herbicides. Elsevier.

Li, H., G. Sheng, B. J. Teppen, C. T. Johnston and S. A. Boyd. 2003. Sorption and desorption of pesticides by clay minerals and humic acid-clay complexes. Soil Sci. Soc. Am J. 67(1): 122-131.

Lima, D. L., R. J. Schneider, H. W. Scherer, A. C. Duarte, E. B. Santos and V. I. Esteves. 2010. Sorption- desorption behavior of atrazine on soils subjected to different organic long-term amendments. J. Agric.Food Chem. 58(5): 31013106.

Ma, Y., J. Zhu, H. He, P. Yuan, W. Shen and D. Liu. 2010. Infrared investigation of organo-montmorillonites prepared from different surfactants. Spectrochimica Acta Part A: Molecular and Biomolecular Spectroscopy. 76(2): 122-129.

Mallakpour, S. and M. Dinari. 2013. Preparation, characterization, and thermal properties of organoclay hybrids based on trifunctional natural amino acids. J. Thermal Analysis Calorimetry. 111(1): 611-618.

McDonald, J., L. Gaston, T. Elbana, K. Andres and E. Cranfield. 2013. Dimoxystrobin Sorption and Degradation in Sandy Loam Soil: Impact of Different Landscape Positions. Soil Sci. Soc. Am J. 178(12): 662-670.
Mockovčiaková, A. and Z. Orolínová. 2009. Adsorption properties of modified bentonite clay. Cheminé Technologija. 1(50): 47-50.

Nir, S., Y. E. Nahhal, T. Undabeytia, G. Rytwo, T. Polubesova, Y. G. Mishael, U. Rabinovitz and B. Rubin. 2006. Clays and Pesticides. In: F. Bergaya, B. K. G. Theng and G. Lagaly eds. Handbook of Clay Science. pp. 677-691. Elsevier Amsterdam.

Nuntiya, A., S. Sompech, S. Aukkaravittayapun and J. Pumchusak. 2008. The effect of surfactant concentration on the interlayer structure of organoclay.

OECD. 2000. Guideline TG 106. OECD Guideline for the Testing of Chemicals. Adsorption- Desorption using a Batch Equilibrium Method. Organization for Economic Co-operation and Development Paris, France.

Oyanedel-Craver, V. A., M. Fuller and J. A. Smith. 2007. Simultaneous sorption of benzene and heavy metals onto two organoclays. J. Colloid Interface Sci. 309(2): 485492.

Park, Y., G. A. Ayoko and R. L. Frost. 2011. Application of organoclays for the adsorption of recalcitrant organic molecules from aqueous media. Journal of colloid and interface science. 354(1): 292-305.

Rebecca, B. 2004. Soil Survey Laboratory Methods Manual. Soil Survey Laboratory Investigations Report. (42): Version 4.0.United States Department of Agriculture.

Rhoades, J. D. 1982. Cation Exchange Capacity In: Methods of Soil Analysis. Part 2. Chemical and Microbiological Properties. Series; Agronomy Monograph, pp. 149-157. Am. Soc. Agron., Soil Sci. Soc. of Am., Madison, WI, USA.

Selim, H. and H. Zhu. 2005. Atrazine sorption-desorption hysteresis by sugarcane mulch residue. J. Environ. Qual. 34(1): 325-335.

Shehata, N., M. S. El-Geundi, E. A. Ashour and R. Abobeah. 2016. Structural Characteristics of the Egyptian Clay as a Low-Cost Adsorbent. Inter. J. Chem.Process Engineer. Res. 3(2): 35-45.

Sikdar, D., K. S. Katti and D. R. Katti. 2008. Molecular interactions alter clay and polymer structure in polymer clay nanocomposites. Journal of nanoscience and nanotechnology. 8(4): 1638-1657.

Srivastava, B., V. Jhelum, D. D. Basu and P. K. Patanjali. 2009. Adsorbents for pesticide uptake from contaminated water: A review. J. Sci. Industrial Res. . 68: 839-850.

Sun, Y., B. Xu, Y. Zhang, B. Liu, Y. Zhou and Z. Su. 2016. Characterization of humic acid modified bentonite binder for iron ore pelletization. In: Characterization of Minerals, Metals, and Materials 2016. pp. 201-208. Springer.

Tan, I., L. Lim and K. Lim. 2013. Removal of atrazine from aqueous solutions using $\mathrm{HNO} 3$ treated oil palm shellbased adsorbent. UNIMAS e-Journal of Civil Engineer. 4(3): 17-22. 
Tiwari, R. R., K. C. Khilar and U. Natarajan. 2008. Synthesis and characterization of novel organo-montmorillonites. Applied Clay Science. 38(3): 203-208.

Trigo, C., W. C. Koskinen, R. Celis, M. J. Sadowsky, M. a. C. Hermosín and J. Cornejo. 2010. Bioavailability of organoclay formulations of atrazine in soil. J. Agric. Food Chem. 58(22): 11857-11863.

Tuovinen, O. h., V. Deshmukh, B. Özkaya and M. Radosevich. 2015. Kinetics of aerobic and anaerobic biomineralization of atrazine in surface and subsurface agricultural soils in Ohio. J. Environ. Sci. Health, Part B. 50(10): 718-726.

Wang, K. and B. Xing. 2005. Structural and sorption characteristics of adsorbed humic acid on clay minerals. J. Environ. Qual. 34(1): 342-349.
Xi, Y., Z. Ding, H. He and R. L. Frost. 2004. Structure of organoclays - an X-ray diffraction and thermogravimetric analysis study. J. Colloid Interface Sci. 277(1): 116-120.

Xi, Y., R. L. Frost, H. He, T. Kloprogge and T. Bostrom. 2005. Modification of Wyoming montmorillonite surfaces using a cationic surfactant. Langmuir. 21(19): 8675-8680.

Yapar, S. 2009. Physicochemical study of microwavesynthesized organoclays. Colloids and Surfaces A: Physicochemical and Engineer. Aspects. 345(1): 75-81.

Zhu, R., Q. Chen, Q. Zhou, Y. Xi, J. Zhu and H. He. 2016. Adsorbents based on montmorillonite for contaminant removal from water: a review. Applied Clay Sci. 123: 239-258.

\section{الملخص العربي \\ إدمصاص وإنطلاق مبيد الأترازين على معدن البنتونيت الطبيعى والبنتونيت المعدل عضوياً محمد على عثمان، فوزى محمد كثك، عبد الله عبد الغفار موسى، هثام محمد جابر}

إرنبـاط (R²>0.95) • بينمـا نتـائج عكس الإدمصـاص كانـت

منطبقة على نموذج Freundlich فقط. وقد تم وصف نتائج

حركية عكس الإدمصـاص بنجاح بإستخدام نموذج تفاعلات

الدرجة الأولى. وأثنارت النتائج أن معدن البنتونيت لـه سعة

إمتصاصية منخفضـة إنعكست في معامل التوزيع حيث بلغ الغ

( $\left.\mathrm{K}_{d}=3.07 \mathrm{~L} \mathrm{Kg}^{-1}\right)$

على زبـادة معامل التوزيـع حيث كان (

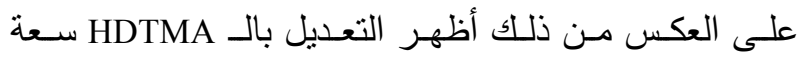

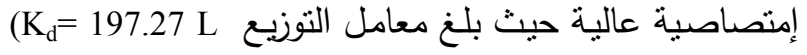

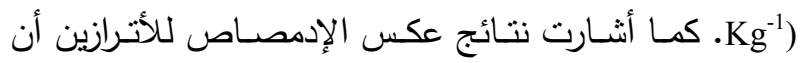

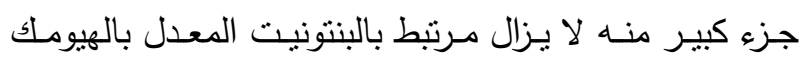

حيث كـان دليـل عـدم الإرتـداد (HI=0.15). أمـا فـى حالـة

البنتونيت المعدل بال HDTMA كانت ظاهرة عدم الإرتداد

منعدمه (HI=1) مما تجعل لله إستخدامات فعالة في مجال

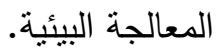

لزيـادة فاعليـة معدن البنتونيــ الطبيعى فى الإحتفـاظ

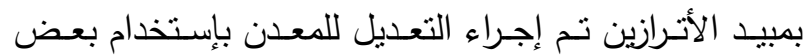

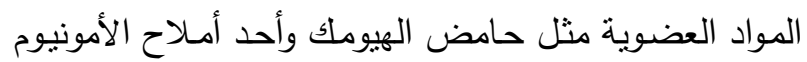

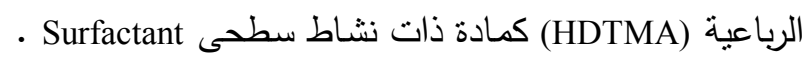

وقد نتج عن هذا التعديل جعل المعدن محب للمواد العضوية

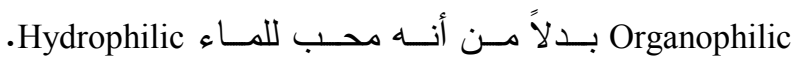
ولتوصيف البنتونيت الطبيعى و المعدل تم الإستعانة بعدد من الطرق مثل تحليل العناصر [CHN] وتقدير مساحة السطح النـوعى وحيـود الأثـعة السـينية والتحليـل الطيفى بالأثـعة

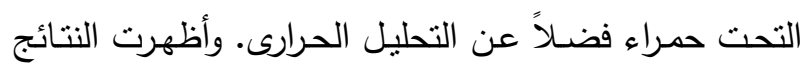
أن التعديل بالمواد العضوية المستخدمه أدى إلى تغير خواص

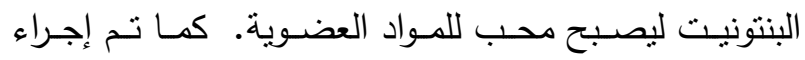
تجارب الإدمصاص وعكس الإدمصاص بالإضافة إلى حركية عكس الادمصـاص لدراسـة سـلوك الأتـرازين علـى معـدن الإدهـ

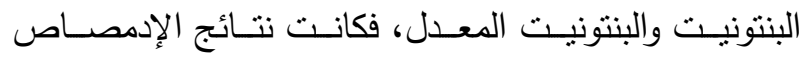

منطبقة على نموذجى Freundlich و Simple linear بمعامل 